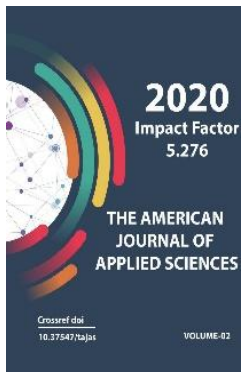

Copyright: Original content from this work may be used under the terms of the creative commons attributes 4.0 licence.

\section{The Influence Of Central Asian Cobra Poison On The Activity Of Rothenon Sensitive And Insensitive Over.H-Oxidase Of Rat Liver Mitochondria And Their Correction With Flavosan (Flateron)}

M. M. Mamajanov

Ph.D, Senior Lecturer Of The Department Of Physiology And Fundamentals Of Valeology, Namangan State University

\title{
ABSTRACT
}

In the presence of cobra venom, the rate of NAD.H oxidation along the internal pathway of the mitochondrial respiratory chain is suppressed, and the rate of NAD.H oxidation along the external pathway increases. These changes occur against the background of cytochrome c deserption from the inner mitochondrial membrane and a significant increase in the process of mitochondrial lipid peroxidation. These facts indicate that when animals are poisoned with cobra venom, profound disturbances are observed in the system of oxidative phosphorylation and the electron transport chain. The introduction of flavosan into the body of animals poisoned with cobra venom leads to an increase in the rate of NAD.H oxidation along the internal pathway of the mitochondrial respiratory chain and suppression of the rate of NAD.H oxidation through the external pathway.

\section{KEYWORDS}

Cobra venom, poison, the rate of NAD.H oxidation, mitochondrial respiratory chain, inner itochondrial membrane, mitochondrial lipid peroxidation

\section{INTRODUCTION}

Actuality of the topic: According to the World Health Organization (WHO), about 0.5 million people suffer annually from poisonous snake bites alone, of which about 40 thousand die [13]. Poisons of snake snakes primarily affect the respiratory center $[1,4]$, the nervous 
system with secondary damage to the blood circulation [1,5], they almost do not cause local changes. Under the influence of cobra venom, many organs, including the liver, usually undergo acute fatty degeneration. In poisoned animals, the protoplasm of the liver cells turns out to be turbid and granular; the number of mitochondria decreases, respiration and oxidative phosphorylation of mitochondria are impaired [6-9]. At the same time, low concentrations of poisons cause dissociation of respiration and oxidative phosphorylation, and large concentrations inhibition of the respiratory function of the mitochondria.

Recently, it was found that the total flavonoid preparation from Thermopsis (Thermopsis alterniflora, legumes - Fadaceae) - flavosan (flateron), low toxicity, its administration orally at a dose of $5000 \mathrm{mg} / \mathrm{kg}$ body weight did not cause a noticeable side effect and death of animals [10].

A study of the effect of flavosan (flateron) on the animal body under hypoxic conditions showed that it markedly increases the resistance of animals to oxygen starvation [11]. The antihypoxic effect of flavosan (flateron) is associated with the economical consumption of oxygen under conditions of hypoxia $[11,12]$.

It was shown that when flavosan (flateron) is introduced into the body of animals against the background of the action of cobra venom, the life expectancy of animals increases. Higher doses of flavosan (flateron) noticeably prevent an increase in gas-oxygen exchange, that is, the body uses oxygen more economically [13], which ultimately leads to an increase in the life expectancy of animals poisoned with cobra venom [14].

And basedn on the above mentioned, we consider that it is important to study the antivenom effects of flavosan (flateron) in case of poisoning of rats with the poison of the Central Asian cobra.

\section{Materials And Methods}

In experimental studies, white male rats weighing an average of 180-200 g were used. The animals were kept on a mixed diet in a well-ventilated, light room, in wooden cages (50x30 cm in size), 6-8 rats each. The rats received food and water ad libitum.

In the experiment, some mechanisms of the antitoxic action of flavosan (flateron) were studied. The poison of the Central Asian cobra Naja naja Oxiana Echwald was chosen as the toxin. The animals were divided into 5 groups of 6-8 each. In the second, third, fourth and fifth groups, the venom of the Central Asian cobra was injected intramuscularly to the animals at a dose of $2 \mathrm{mg} / \mathrm{kg}$ body weight [14]. After $2 \mathrm{~min}$, the animals of the second, third and fourth groups were additionally injected with flavosan (flateron) - 250, 500 and $750 \mathrm{mg} / \mathrm{kg}$ of body weight, respectively. The first group of rats received saline. The animals were decapitated 15 min after the introduction of the cobra venom.

The poison of the Central Asian cobra was obtained from the Institute of Zoology of the Academy of Sciences of the Republic of Uzbekistan. In this work, we used samples of the poison from the collection of 2010 and 2011, dried in a desiccator over calcium chloride.

Mitochondria were isolated from the liver tissue of animals using the generally accepted method of differential centrifugation [15] with some modifications [16]. The rats were sacrificed, the liver was removed and immersed in a beaker with an isolation medium of the following composition: sucrose $300 \mathrm{mM}$, Tris-HC1 - $10 \mathrm{mM}$, EDTA - $2 \mathrm{mM}$. The liver was cleaned of foreign tissues (fat, connective tissue), then its weight was 
determined by weighing, crushed with scissors and placed in a tenfold volume of precooled isolation medium compared to the organ and homogenized for 30-40 $\mathrm{s}$ in a combined homogenizer with a Teflon pestle having a threaded knife block with a cloth feeding device.

The activity of the mitochondrial polyenzyme systems was determined after freezing and thawing of mitochondria. NAD.H-oxidase activity was assessed by adding $3 \mu \mathrm{mol}$ NAD.H. to a $1 \mathrm{ml}$ cell. NAD.H-oxidase activity was also determined in the presence of $2 \mu \mathrm{g}$ of rotenone. Change medium: $0.66 \mathrm{M}$ sucrose containing $50 \mathrm{mM}$ Tris- $\mathrm{HCl}, \mathrm{pH} 7.4$ and $5 \mathrm{mM}$ histidine [17]. The activity of oxidase systems in mitochondria was recorded polarographically using a rotating platinum electrode under standard conditions in a $1 \mathrm{ml}$ polarograph cell at $25^{\circ} \mathrm{C}$. The protein content was determined by the Lowry method [18].

\section{RESULTS AND DISCUSSIONS}

It is known that liver mitochondria has two oxidation systems - an internal phosphorylating pathway for the oxidation of succinate and substrates oxidized through $N A D$, and an external pathway for free oxidation of added NAD.H; the initial part of the respiratory chain of this pathway is NAD.H2-cytochrome b5-reductase [19]. One of these oxidation pathways is inhibited by rotenone (internal oxidation pathway). Table 1 shows the results of a separate determination of the rates of NAD.H oxidation by the internal and external pathways at $250 \mathrm{C}$. It can be seen that the introduction into the animal organism of $2 \mathrm{mg}$ of cobra venom per $\mathrm{kg}$ of body weight of cobra venom, the rate of NAD.H oxidation along the respiratory chain is $41.2 \%$ of the control. At the same time, the rate of NAD.H oxidation by the external - rotenone insensitive pathway of NAD.H oxidation increased by $95.7 \%$.

Table 1

Influence of flavosan (flateron) on the internal and external pathways of NAD.H oxidation of mitochondria against the background of rat poisoning with cobra venom $(M \pm m ; n=6$ -

7)

\begin{tabular}{|c|c|c|c|}
\hline \multirow{2}{*}{ Variant } & $\begin{array}{c}\text { Flavo-san } \\
\text { doses, } \mathrm{mg} /\end{array}$ & \multicolumn{2}{|c|}{$\begin{array}{c}\text { Respiration rate, nanogram oxygen atom / min } \\
\text { mg protein }\end{array}$} \\
\cline { 3 - 4 } & $\mathrm{kg}$ & $\begin{array}{c}\text { Internal oxidation path } \\
\text { NAD.H }\end{array}$ & $\begin{array}{c}\text { External oxidation path } \\
\text { NAD.H }\end{array}$ \\
\hline Healthy animals & 0 & $61,24 \pm 5,05$ & $4,60 \pm 0,42$ \\
\hline Poisoned animals & 0 & $36,01 \pm 4,21^{* * * *}$ & $9,00 \pm 0,77^{* * * *}$ \\
\hline
\end{tabular}




\begin{tabular}{|l|l|l|l|}
\hline & 250 & $42,62 \pm 4,00^{* * * *}$ & $7,81 \pm 0,53^{* * *}$ \\
\hline & 500 & $49,84 \pm 4,67^{* * *}$ & $6,90 \pm 0,38^{* * *}$ \\
\hline & 750 & $54,45 \pm 3,85^{* *}$ & $5,92 \pm 0,32^{*}$ \\
\hline
\end{tabular}

Note: here the degree of reliability of the differences: * $\mathrm{P}<0.05 ; * * \mathrm{P}<0.02 ; * * * \mathrm{P}$

$$
<0.01 ; * * * * \mathrm{P}<0.001 \text {. }
$$

Thus, these data indicate that inhibition of the respiratory activity of the inner membrane and an increase in the external pathway of mitochondrial oxidation is one of the earliest functional disorders of mitochondria when animals are poisoned with cobra venom.

The introduction of flavosan (flaterone) against the background of animal poisoning with cobra venom leads to the normalization of the internal and external pathways of NAD oxidation of mitochondria, and these changes depended on the dose of flavosan (flaterone). So, if after the introduction of 250, 500 and $750 \mathrm{mg}$ of flavosan (flateron) per kg of animal body weight, the external pathway of NAD.H oxidation increases by 69.8 , respectively; 50.0 and $28.7 \%$ of the normal level, then the internal path decreases - 30.4; 18.6 and $10.6 \%$. This means that flavosan (flateron) stabilizes the inner mitochondrial membrane and inhibits the elimination of cytochrome $c$ from the membrane.

In our opinion, the conditions for activation of the external pathway of NAD.H oxidation and inhibition of the internal pathway of substrate oxidation in animals poisoned with cobra venom is the desorption of cytochrome from the inner mitochondrial membrane into the intermembrane space, resulting in the connection of the flavin5-cytochrome b5 system to cytochrome oxidase. These results indicate a deep disruption of the conjugation between the protein-phospholipid bonds of the inner mitochondrial membrane during swelling $[20,21]$. Membrane disorders associated with changes in phospholipids significantly alter the ability of the inner mitochondrial membrane to accept cytochrome c [21, 22]. These characteristics are very sensitive to the formation of membrane damage and change even with small degrees of "hidden" damage [22]. In our opinion, the cleavage of phospholipids of the inner mitochondrial membranes by endogenous phospholipases under the action of cobra venom leads to disruption of the function of a free-floating carrier of reducing equivalents from dehydrogenases to cytochrome chains - coenzyme Q [23]. There are three coenzyme $\mathrm{Q}$ binding sites in the respiratory chain: 1) researched and characterized by L.S. Yaguzhinsky and sotr. [24] a hydrophobic site in succinate dehydrogenase; 2 ) a section of the respiratory chain between cytochromes $b$ and $c 1$, where antimycin A, 2-hydroxy-3-alkylbenzo- and naphthoquinones bind; 3 ) the site of rotenone binding in NAD.H-dehydrogenase [23]. At these points of coenzyme $\mathrm{Q}$ binding, the interaction of the coenzyme core with the corresponding enzyme is carried out due to different functional groups of the coenzyme Q molecule [24].

Side Panels Damaged mitochondria trigger the release of cytochrome $c$ through the mitochondrial pores [25]. The released cytochrome $c$ is the "death sentence" of the cell [26]. Cytochrome c entails the transmission of an apoptosis signal, which often results in various diseases. Thus, in many apoptotic neurons during the development of the nervous system in vertebrates, the loss of cardiolipin, an easily oxidized phospholipid, which is part of the inner mitochondrial membrane, occurs. It was shown that the 
content of cardiolipin decreases before the disappearance of mitochondria in these cells, and by the time of loss of cardiolipin the mass of mitochondria decreases insignificantly. And the fact that the disappearance of cardiolipin is competitively associated with the production of reactive oxygen species by mitochondria and an increase in lipid peroxidation indicates the participation of free oxygen radicals in these processes [27]. This is well correlated with the message of fundamental importance about the two-stage process of release of cytochrome $c$ from the mitochondria of apoptotic cells. At the first stage, cytochrome $\mathrm{c}$ is separated from the inner mitochondrial membrane, where it is associated with cardiolipin due to electrostatic and / or hydrophobic interactions. This separation occurs after the oxidative modification of cardiolipin. The subsequent increase in the permeability of the outer mitochondrial membrane under the action of the Bax oncoprotein leads to the release of cytochrome c from mitochondria [28]. The loss of molecular interaction between cytochrome $c$ and cardiolipin, caused by lipid peroxidation, was reported by other researchers somewhat earlier [29]. It is the modification of cardiolipin under the conditions of lipid peroxidation that induces the release of cytochrome $c$ from mitochondria into the cytosol, which is one of the important initial stages of apoptosis.

Cytochrome c, released from the mitochondrion into the cytosol, binds to a cytosolic protein called "the first factor activating apoptosis" (Apaf-1). Apaf-1 also binds to deoxyATP (dATP) and several molecules of procaspase 9 (an inactive precursor of caspase 9, a special protease enzyme) [30-32]. After the formation of the complex, procaspase 9 is cleaved into caspase 9 and a shorter peptide that does not have any activity. Caspase 9 attacks procaspase 3, cleaving it to form active caspase 3. Caspase 3 is a protease that proteases enzymes that occupy key positions on the metabolic map of the cell, as well as nuclease precursor proteins and structural proteins. Ultimately, all of this ATPase is either inactivated by the oxidized form of phosphatidylserine, or simply does not recognize the oxidized phospholipid. That is why the oxidation of phosphatidylserine by ROS leads to its appearance in the outer layer of the plasma membrane. Apparently, there is a special receptor that detects phosphatidylserine in the outer lipid layer. It is assumed that this receptor, by binding phosphatidylserine, sends a signal of apoptosis inside the cell.

Here, first of all, we are not interested in what further processes and in what role the released cytochrome $c$ is involved, but the very fact of its release from mitochondria. From our point of view, this seemingly simple act is very important, since, as a positive feedback, it supports the disruption of the transport of electrons in the respiratory chain, reduces the utilization of $\mathrm{O}_{2}$ by mitochondria and, therefore, contributes to its accumulation in the cell and the stability of the state necessary for apoptosis oxidative stress, first in the mitochondria, then in the cytoplasm and within the entire cell. In addition, positive feedback on the maintenance of oxidative stress in cells is realized, apparently, through other channels. One of them is the active forms of oxygen dependent damage to mitochondrial DNA (mtDNA) with the formation and accumulation, in particular, of 8-hydroxy-2? deoxyguanosine. True, this oxidative damage to mtDNA is repaired to some extent [33]. Another channel of such feedback can act through oxidative damage to mtDNA polymerase, which should lead to a decrease in mtDNA replication [34] and, accordingly, to a weakening of the mitochondrial base. Thus, in mitochondria, there are different ways to maintain the oxidative stress that has arisen in them not below a certain level. 


\section{CONCLUSION}

After analyzing the results, we can conclude that in the presence of cobra venom, the rate of NAD.H oxidation along the internal pathway of the mitochondrial respiratory chain is suppressed, and the rate of NAD.H oxidation along the external pathway increases. These changes occur against the background of cytochrome $c$ deserption from the inner mitochondrial membrane and a significant increase in the process of mitochondrial lipid peroxidation. These facts indicate that when animals are poisoned with cobra venom, profound disturbances are observed in the system of oxidative phosphorylation and the electron transport chain. The introduction of flavosan (flaterone) into the body of animals poisoned with cobra venom leads to an increase in the rate of NAD.H oxidation along the internal pathway of the mitochondrial respiratory chain and suppression of the rate of NAD.H oxidation through the external pathway.

\section{REFERENCES}

1. Orlov B.N., Valtseva I.A. Snake venoms. Tashkent: Medicine, 1977, $250 \mathrm{~S}$.

2. Orlov B.N., Geliashvili D. B. et al. Physiological mechanisms of the neurotropic action of snake venoms. Success fiziol. Sciences, Moscow. 1979. Vol.10. \# 2. p.24-44.

3. Isaev I.V., Kovaleva S.V. and other Biological and physical and chemical properties, composition and use of snake venoms. - Questions of biological, medical and pharmaceutical chemistry. Moscow. 2000. No. 3. p. 1423.

4. Allamuratov Sh.l., Sultonov Sh. Et al. Gas-oxygen exchange in mice under the action of lethal and non-lethal doses of zootoxins. - Biology va ecology xozirgi zamon muammolari, ToshDU, II ism. 1995. P.19.

5. Harutunyan R.A., Voskanyan A.V., Arutunyan K.R., Martirosyan S.Sh. Study of the influence of bee venoms and some snake species on thermoregulation in rats. - Russian fiziol. magazine them. THEM. Sechenov. St. Petersburg. 2000. Vol. 86. No. 2. p. 210-215.

6. Sakhibov D.M., Sorokin V.M., Yukelson L.Ya. Chemistry and biochemistry of snake venom. Tashkent: Fan, 1972. P. 186.

7. Sattyev R. Influence of the venoms of Central Asian snakes on the structure and function of mitochondria: Dis.... Cand. biol. sciences. - Tashkent: Institute of Biochemistry, ANRUz. 1974. P. 147.

8. Sultonov Sh.K., Holmatov R.Sh. and other Features of the effect of toxic doses of gyurza and cobra venom on respiration of liver mitochondria in rats and desert turtles in vivo. - In the book: Organism and Environment. Fan: Tashkent, 1995, p. 182-183.

9. Almatov K.T., Dzhamalova A.T. et al. Influence of the Central Asian cobra venom and its fractions with phospholipase A2 activity on oxidative phosphorylation in liver mitochondria. - Bulletin of Tashkent State University named after M. Ulugbek, 1998, No. 2 p.10-14.

10. Khushbaktova Z.A. Pharmacological studies of new cardenolides, cycloartonic glycosides, their transformation products and polyphenolic compounds. - Author's abstract. diss ... doct. biol. sciences, Tashkent, 1997, p. 32.

11. Mamazhanov M.M., Khushbaktova Z.A., Almatov K.T. Influence of flavosan on basal metabolism and energy metabolism of mitochondria of some rat organs. - In collection: Actual 
problems of biology, ecology and soil science. Theses of the report. Tashkent, 2006, p. 74.

12. Rakhimova Sh., Mamazhanov M.M. Hypoxia flavosanni asosiy almashinuvga tatsiri. - Actual problems of biology, ecology and soil science. Theses of the report. Tashkent, 2007, p. 83.

13. Almatov K.T., Mamazhanov M.M. et al. Effect of flavosan on the basal metabolism of animals poisoned with the poison of the Central Asian cobra Naja naja O [iana Echwald. - In collection: "Physikaviy-kimeviy biology va biotechnology istiқbollari”. Abstracts of reports. Andijon, 2007, pp. 276-277.

14. Almatov K.T., Mamazhanov M.M., Khushbaktova Z.I. Anti-venom actions of flavosan. - In collection: "Physikaviykimeviy biology va biotechnology istikbollari". Abstracts of reports. Andijon, 2007, pp. 274-276.

15. Schneider W.C., Hogeboom G.N. Cytochemical studies of mammalian tissues the isolation of cell components by differential centrifugation. Cancer. Res. 1951. V. 19. P. 1-22.

16. Almatov K.T., Yusupova U.R., Abdullav G.R. wa b. Organizmning nafas olishi va energija khosil қilishini aniқlash, Tashkent. 2013 .-- p. 103.

17. Rakhimov M.M., Almatov K.T. Some features of the degradation of polyenzyme systems of liver mitochondria in rats exposed to heat. Biochemistry. Moscow. 1977. T. 42. No. 10. p. $1852-1863$.

18. Lowry O.H., Rosebrough N.J., Farr A.L., Randall R.J. Protein measurement with the Folin phenol reagent. - J. Biol. Chem. 1951. V. 193. N. 1. P. 265-274.

19. Skulachev V.P. Energy accumulation in the cell. Moscow: Science. 1969.
20. Almatov K.T., Rakhimov M.M. Latent damage to the mitochondrial polyenzyme systems. - Uzbek. biol. zhurn. 1977, No. 4, pp. 3-6.

21. Agzamov H. Study of hidden damage to the polyenzyme systems of the inner mitochondrial membrane in pathology and stress. - Diss .... uch. Senior Candidate of Biological Sciences Tashkent. 1982.

22. Almatov KT, Agzamov Kh., Rakhimov MM, Turakulov Ya.Kh. Quantification of latent damage in mitochondrial membranes. - Uzbek. biol. Journal. 1981. No. 2. p. 3-7.

23. Lenaz $\mathrm{G}$. The role of lipids in the structure and function of membranes. In: Subcellular biochemictry. - Ancona, Italy. 1979. N.6. P. 233-317.

24. Kostyrko V.A., Kolesova G.M. et al. On the nature of the interaction of inhibitors with the binding sites of $\mathrm{CoQ}$ in the respiratory chain of mitochondria. - Mitochondria. Energy accumulation and regulation of enzymatic processes. Moscow: Science. 1977. P.116-123.

25. Yang J., Liu X. et al. Prevention of apoptosis by $\mathrm{Bcl}-2$ : Release of cytochrome $c$ from mitochondria blocked. - Science, 1997. V. 275. N. 5303, P. 1129-1132.Green D. R., Reed J. C. Mitochondria and apoptosis. Science, 1998. V. 281. N 5381, P. 13091312.

26. Kikland R. A., Adiphatla R. M., Hatcher J. F., Franklin J. L. Neuroscience. 2002. V. 115. № 2. P.587.

27. Ott M., Robertson J. D., Gogvadze V., Zhivotovsky B., Orrenius S. Proc. Nat. Acad. Sci. USA. 2002, V. 99. №3. P. 1259.

28. Shidolji Y., Hayashi K., Komura S., Ohishi N., Yagi K. Biochem. and Biophys. Res. Commun. 1999. V. 264. № 2.P. 343. 
29. V. P. Skulachev In its intermembrane space, the mitochondrion harbors a "suicide protein", which, when released into the cytosol, causes apoptosis. - Biochemistry. Moscow. 1996. Vol. 61. Issue 11. p. 2060-2063.

30. V. P. Skulachev Oxygen and the phenomena of programmed death. (The first Severin reading, read on December 21, 1999). Moscow, 2000, p.

47.

31. V. P. Skulachev Phenomena of programmed death. Mitochondria, cells and organs: the role of reactive oxygen species. Soros Educational Journal. 2001, T. 7, No. 6, p. 4-10.

32. Bohr V. A., Stevnsner T., de SouzaPinto N. C Gene. 2002. V. 286. No. 1. P. 127.

33. Graziewicz M. A., Day B. J., Copeland W. C. Nucl. Acids Res. 2002. V. 30. No. 13. R. 2817. 